\title{
Obesity, CTCAE
}

National Cancer Institute

\section{Source}

National Cancer Institute. Obesity, CT CAE. NCI Thesaurus. Code C55334.

A disorder characterized by having a high amount of body fat. 